\author{
Borko N. Kovačević \\ Univerzitet u Beogradu \\ Filološki fakultet**
}

https://doi.org/10.18485/analiff.2018.30.1.15

811.163.41'367.622.16

Originalni naučni rad

Primljen: 05.05.2018.

Prihvaćen: 12.07.2018.

\title{
O POLISEMIČNIM GLAGOLSKIM IMENICAMA U SAVREMENOM SRPSKOM JEZIKU
}

\begin{abstract}
U radu se analiziraju polisemične (dvosmislene) glagolske imenice u savremenom srpskom jeziku. U pitanju su četiri grupe ovakvih imenica: imenice koje imaju interpretaciju imenice koja označava događaj i imenice koja označava argument događaja; imenice koje pripadaju i imenicama koje označavaju događaj i rezultativnim imenicama; imenice koje pripadaju imenicama koje označavaju događaj i referencijalnim imenicama; imenice koje pripadaju imenicama koje označavaju argument događaja i referencijalnim imenicama. Najveći polisemični kapacitet imaju imenice sa značenjem događaja.
\end{abstract}

Ključne reči: glagolske imenice, polisemija, savremeni srpski jezik

\section{Uvod}

Predmet ovog rada su polisemične, tačnije dvosmislene glagolske imenice - imenice izvedene iz glagola koje imaju dva značenja. Pod glagolskom imenicom se ovde (kao i u Kovačević 2016) podrazumeva kategorija koja je izvedena iz glagola i funkcioniše kao imenica, bez obzira na njeno značenje i sufiks kojim je izvedena. Za svrstavanje određenog oblika u klasu glagolskih imenica kao jedini kriterijum uzima se (glagolsko) poreklo tog oblika (imenice).

Zasnovano na međujezičkim (kroslingvističkim) istraživanjima ${ }^{1}$ i pri-

\footnotetext{
* Katedra za opštu lingvistiku, Filološki fakultet, Studentski trg 3, 11000 Beograd, borko.kovacevic@fil.bg.ac.rs.

** Rad je nastao u okviru projekata Standardni srpski jezik: sintaksička, semantička i pragmatička proučavanja, koji finansira Ministarstvo prosvete, nauke i tehnološkog razvoja Republike Srbije (projekat br. 178004).

1 Na prvom mestu se misli na istraživanja Sleeman \& Brito (2010a, 2010b), koja su inspirisana takozvanim strukturnim pristupom A. Alexiadou (2001, 2009). Ovaj pristup se nadovezuje na istraživačka usmerenja u okviru transformaciono-generativne gramatike čiji je začetnik N. Chomsky u svom radu Zabeleške o nominal-
} 
meni istih na srpski jezik, u Kovačević (2016) se navodi podela glagolskih imenica u savremenom srpskom jeziku na četiri potkategorije: 1) imenice koje označavaju događaj, 2) imenice koje označavaju argument događaja, 3) menice koje označavaju rezultat događaja (rezultativne imenice) i 4) referencijalne imenice. Dajući jednu sveobuhvatnu, međujezičku sliku klasifikacije glagolskih imenica, Kovačević (2016) navodi da se glagolske imenice u srpskom mogu podeliti na dve opšte klase: imenice sa obeležjem +događaj i imenice sa obeležjem - događaj. U imenice sa obeležjem +događaj spadaju imenice koje se na bilo koji način odnose na događaj. To su imenice koje označavaju (sam) događaj, imenice koje označavaju argument događaja i imenice koje označavaju rezultat događaja (=rezultativne imenice). U imenice koje označavaju sam događaj spadaju semantički gledano prave glagolske imenice, odnosno, kako se to tradicionalno definiše, imenice koje imaju glagolsko značenje - značenje ,radnje, stanja ili zbivanja” (kopanje, patnja, svitanje). Među imenicama koje označavaju argument događaja razlikuju se imenice sa značenjem eksternog argumenta (čitalac, takmičar, graditelj) i imenice sa značenjem internog argumenta (ranjenik, osuđenik). Rezultativne imenice, kao što sam naziv kaže, su imenice koje označavaju rezultat nekog događaja (rešenje, pozajmica, otkriće). U imenice sa obeležjem -događaj spadaju referencijalne glagolske imenice. U potkategoriji referencijalnih imenica semantički se izdvajaju četiri grupe: imenice sa značenjem profesije, titule, ili zanimanja (učitelj, glumac); imenice sa značenjem životinja i biljaka (glodar, puzavica); imenice sa značenjem predmeta (upaljač, dizalo) i imenice sa značenjem mesta (gradilište, sušara). ${ }^{2}$

Svaka imenica izvedena iz glagola može se svrstati u jednu od navedenih potkategorija. Postoje međutim i slučajevi da jedna imenica pokazuje osobine koje su karakteristične za dve vrste glagolskih imenica, odnosno da pripada dvama potkategorijama. Semantički govoreći, u pitanju su polisemične, dvosmislene glagolske imenice. U daljem toku rada analiziraju se neki primeri ovakvih imenica. Zabeležene su četiri mogućnosti dvosmislenosti glagolskih imenica: imenica može imati interpreta-

izaciji (Remarks on nominalization, 1970), a koja su kasnije razrađivali neotransformacionalisti (Lebaux 1986; Picallo 1991; Borer 1993, 2003; van Hout \& Roeper 1998; Borsley \& Kornfilt 2000; Fu et al. 2001), kao i Grimshaw (1990).

2 Svaka od četiri potkategorije glagolskih imenica ima neke svoje sintaksičkosemantičke osobine po kojima se jasno razlikuje od ostale tri potkategorije. Detaljnije o ovim osobinama v. u Kovačević (2016). 
ciju imenice koja označava događaj i imenice koja označava argument događaja; imenice koja označava događaj i rezultativne imenice; imenice koja označava događaj i referencijalne imenice; kao i interpretaciju imenice koja označava argument događaja i referencijalne imenice. Svi primeri preuzeti su iz Korpusa savremenog srpskog jezika na Matematičkom fakultetu u Beogradu. ${ }^{3}$

\section{Imenice koje pripadaju i imenicama koje označavaju događaj i rezultativnim imenicama}

Među imenicama koje pripadaju dvema potkategorijama glagolskih imenica najviše je imenica koje mogu da pripadaju i imenicama koja označavaju događaj i rezultativnim imenicama. U narednim parovima primera u prvom primeru je upotrebljena imenica koja označava događaj, a u drugom rezultativna imenica:

Dostava naručenih pica je besplatna.

... Skoplje - Kičevo u petak uveče (26. januara), kod mesta Zajas, juče je, nešto posle 16 časova, zbog anonimne dostave da je na glavnoj skopskoj železničkoj stanici postavljena bomba, saobraćaj više od dva časa bio prekinut.

Sve u svemu, nije Zvezdin oproštaj od Evrope bio, cifarski gledano, nedostojanstven. Sutradan je došla i molila za milost, pala mi je pred noge i dobila oproštaj.

Umesto korektorskog odeljenja, ispravke grešaka učinio je sam autor. Spremni na saradnju, kako vam se ovakve greške ubuduće ne bi događale, očekujemo da objavite ovu ispravku.

Ta prepiskase odvijala na srpskom, pa ću ja noćas još morati da vežbam engleski. ... univerzitetskoj biblioteci u Beogradu, i oko dve hiljade starih i važnih dokumenata, među kojima je posebno značajna prepiska kneza Miloša i kneza Mihajla do koje je Joca Vujić došao u Temišvaru.

Mudri Homer nije se upuštao u opis lepe Jelene, a lepotice na kraju ovog milenijuma video je ceo svet i svako ima svoju kombinatoriku o tome koja je najlepša. Poslaše mu opis bolesti, da bi ga on pokazao nekom doktoru koji leči putem dopisivanja.

3 Primeri su prvobitno navedeni u Kovačević (2012). 
... je podsetio da SRS već godinama trpi pritiske i pretnje od strane crnogorskog režima, blokadu u tamošnjim medijima, ali je dodao da je stranka, uprkos tome, u Crnoj Gori dobro ...

Pretnja je stigla u pisanom obliku, došla je na naš faks u Uredu predsednika.

Ekološkim porezom socijaldemokratsko-zelena vlada želi da podstakne štednju energije i poveća svest građana o korišćenju prirodnih resursa.

Devizna štednja će se isplaćivati preko poslovnih banaka na celoj teritoriji Jugoslavije, uključujući i banke u Repblici Crnoj Gori.

To bi automatski značilo izdvajanje Nemačke iz "velike četvorke", koju još čine Francuska, Velika Britanija i Italija.

Izdvajanja SAD za ove svrhe veća su nego sledećih 15 zemalja na listi zajedno!

Od pomoći je i slušanje muzike, pevanje na stranom jeziku, učenje napamet stihova i proznih odlomaka, budući da se struktura jezika teže zaboravlja nego reč. U jedinstvenoj ustanovi na svetu, psihoanalitičkom Geringovom institutu, u nacističkoj Nemačkoj, Frojdovo učenje dobilo je sasvim novu namenu, u skladu s potrebama nove arijevske rase.

S tim u vezi, izdata su posebna uputstva zdravstvenim ustanovama u kojima se sprovodi namerni prekid trudnoće i bankama preko kojih se ova sredstva uplaćuju, kaže se u saopštenju Ministarstva za zdravlje Republike ...

Popravljen je i prekid na kablu kod sela Prilužje, koji su Albanci pre pet dana presekli sekirom.

Navedeni primeri odlično ilustruju činjenicu da glagolske imenice u srpskom jeziku ne čuvaju kategoriju glagolskog vida (glagola iz kojeg su izvedene), odnosno da imenice nastale od nesvršenih glagola ne označavaju uvek proces vršenja glagolske radnje (nesvršenu glagolsku radnju), a one od svršenih glagola svršetak, odnosno rezultat radnje.

Još je Belić (1933: 265) izričito tvrdio da ,imenice sagrađene od svršenih glagola moraju imati rezultativno značenje, tj. moraju značiti ili predmet kao rezultat radnje, ili kakav čin ili uopšte imenicu izvesne vrste." O tome da se od nesvršenih glagola obično grade imenice koje imaju značenje procesa vršenja glagolske radnje, a od svršenih glagola obično rezultativne imenice govore i Vuković (1950), Terzić (1969) i Radić (1988). Međutim i Vuković (1950) i Terzić (1969), a kasnije i Klajn (2003), pokazuju da ovo načelno pravilo ima svoje izuzetke.

Pozivajući se na Vukovića i Terzića, Klajn (2003: 175) ističe da i pored toga što generalno imenica od nesvršenog i imenica od odgovara- 
jućeg svršenog glagola stoje međusobno u vidskoj opoziciji (skraćivanje : skraćenje), postoje brojni izuzeci koji pokazuju da ove imenice ne čuvaju vid glagola od kojeg su nastale.Vuković i Terzić navode primere koji svedoče o mešanju vidova kod ovih imenica: imenice od svršenih glagola upotrebljavaju se u kontekstima u kojima po smislu treba da dođu imenice koje su nastale od nesvršenih glagola, a imenice od nesvršenih glagola $\mathrm{u}$ kontekstima kojima više odgovaraju imenice od svršenih glagola. Upotreba imenice od svršenog glagola umesto imenice od nesvršenog glagola najviše upada u oči u primerima gde se uz ovakve imenice upotrebljavaju izrazi kojima se izrazito obeležava trajanje glagolske radnje. Takav je primer ,neprekidno povišenje njihovog životnog standarda” (Vuković 1950: 48). Prilog neprekidno implicira trajanje glagolske radnje i upotrebljava se sa nesvršenim glagolom povišavati, a ne sa njegovim svršenim parnjakom povisiti. Očekivana bi bila upotreba ovog priloga uz imenicu nastalu od glagola povišavati - povišavanje, a ne uz imenicu od glagola povisiti - povišenje. Slični su i primeri: ,pratiti izvršenje plana” i „u toku izvršenja” (izvršenje umesto izvršavanje). Terzić (1969: 67) govori o tendenciji da se očuva samo glagolska imenica od jednog glagola iz vidskog para na uštrb imenice od drugog glagola, koja se povlači iz upotrebe. Poskupljenje se sve češće upotrebljava umesto poskupljivanje, pogoršanje umesto pogoršavanje, izlečenje umesto izlečivanje, povećanje umesto povećavanje, venčanje umesto venčavanje, osvetljenje umesto osvetljavanje. Slučaj da glagolske imenice sa sufiksom -nje koje su izvedene od nesvršenih glagola imaju značenje ograničenosti, rezultativnosti radnje, ilustruju sledeći primeri (Terzić 1969: 67): hapšenje (može da znači i ,uhapšenje”), oduzimanje (upotrebljava se i u rezultativnom značenju umesto imenice „oduzeće"), sužavanje (može značiti i ,suženje”), objavljivanje (u značenju „objava”, „objavljenje”) i slično. ${ }^{4}$

U slučaju opozicije imenica sa značenjem događaja : rezultativna imenica, u kontekstu kojem odgovara imenica sa značenjem događaja trebalo bi da se upotrebi imenica izvedena iz nesvršenog glagola, a u kontekstu kojem odgovara rezultativna imenica, trebalo bi da se upotrebi imenica izvedena iz svršenog glagola. Međutim, u svim gorenavedenim parovima

4 Klajn, Vuković i Terzić govore o imenicama izvedenim sufiksom -nje. Kao što pokazuju primeri iz ovog istraživanja, njihovi zaključci mogu se primeniti i na glagolske imenice izvedene drugim sufiksima. 
primera upotrebljena je samo jedna (polisemična, dvosmislena) imenica, izvedena iz jednog (svršenog ili nesvršenog) glagola.

U prvom paru primera, u oba konteksta (i u kontekstu gde se očekuje imenica sa značenjem događaja i u rezultativnom kontekstu) upotrebljena je imenica izvedena iz svršenog glagola - dostava. Samo se u prvom primeru, u slučaju imenice sa značenjem događaja, imenica dostava može zameniti imenicom dostavljanje (koja je izvedena iz nesvršenog glagola i koja je „očekivana” u kontekstu imenice sa značenjem događaja), što nije moguće u drugom primeru (gde imenica dostava ima rezultativnu interpretaciju): Dostavljanje naručenih pica je besplatno nasuprot *anonimno dostavljanje da je na glavnoj skopskoj železničkoj stanici postavljena bomba. Ista je situacija i u naredna četiri para primera (imenice oproštaj, ispravka, prepiska i opis). I u ovim primerima je upotrebljena imenica izvedena iz svršenog glagola i samo se u slučaju interpretacije imenice sa značenjem događaja može upotrebiti imenica izvedena iz nesvršenog glagola: Zvezdino opraštanje od Evrope/*pala mi je pred noge $i$ dobila opraštanje; ispravljanje grešaka učinio je sam autor/*očekujemo da objavite ovo ispravljanje; Homer se nije upuštao u opisivanje lepe Jelene/*Poslaše mu opisivanje bolesti. Posebno su zanimljivi primeri sa imenicom prepiska, odnosno prvi primer, koji ima interpretaciju imenice sa značenjem događaja. U primeru Ta prepiska se odvijala na srpskom, u kontekstu imenice sa značenjem događaja upotrebljena je imenica izvedena iz svršenog glagola (prepisati). Ta imenica se u ovom kontekstu, kao i imenice u prethodna četiri primera (dostava, oproštaj, ispravka i opis), može zameniti imenicom koja je izvedena iz nesvršenog glagola. Međutim, to nije imenica prepisivanje (koja je izvedena iz nesvršenog glagola prepisivati, koji je parnjak svršenog glagola prepisati), nego imenica dopisivanje, koja je izvedena iz nesvršenog glagola dopisivati se: To dopisivanje se odvijalo na srpskom. ${ }^{5}$ Radi se o tome da imenica prepiska u kontekstu imenice sa značenjem događaja ima značenje koje nema glagol prepisati iz kojeg je izvedena (a ni njegov nesvršeni parnjak, glagol prepisivati), nego značenje jednog drugog glagola - glagola dopisivati se.

Poslednjih pet parova primera (sa imenicama pretnja, štednja, izdvajanje, učenje i prekid) ilustruju situaciju da se i u kontekstu gde se očekuje

$5 \quad$ Gramatički je ispravan i primer To prepisivanje se odvijalo na srpskom, ali ima drugačije značenje. 
imenica sa značenjem događaja i u rezultativnom kontekstu upotrebljava imenica izvedena iz nesvršenog glagola. Zamena imenicom koja je nastala od svršenog glagola je u većini primera nemoguća. Imenica ?zaprećenje, kao parnjak imenice pretnja, zvuči čudno i teško je uopšte naći kontekst u kome bi se upotrebila. Ista je situacija i sa imenicom ?izdvojenje (od glagola izdvojiti, koji je svršeni parnjak glagola izdvajati) i imenicom ?prekinuće (od glagola prekinuti, koji je svršeni parnjak glagola prekidati). Iz glagola naučiti (koji je svršeni parnjak glagola učiti) izvedena je imenica nauk, koja se može upotrebiti umesto imenice učenje samo u rezultativnom kontekstu: Frojdov nauk je dobio sasvim novu namenu/*nauk napamet stihova. Ovaj primer je gramatički ispravan i prihvatljiv, ali semantički ne predstavlja zamenu primera Frojdovo učenje, jer imenica nauk ima drugačije značenje od imenice učenje.

Imenica ušteda (od glagola uštedeti, koji je svršeni parnjak glagola štedeti) se može upotrebiti u kontekstu imenice sa značenjem događaja (vlada želi da podstakne uštedu energije), ali ne može u kontekstu rezultativne imenice (?devizna ušteda će se isplaćivati). Ovo je zanimljiv primer jer bi bila očekivana obrnuta situacija, odnosno da se imenica izvedena iz svršenog glagola može upotrebiti u rezultativnom značenju, ali ne i u kontekstu imenice sa značenjem događaja.

Nešto je manji broj primera u kojima se pojavljuju imenice koje pokazuju dvosmislenost između imenice sa značenjem argumenta događaja i referencijalne imenice.

\section{Imenice koje pripadaju i imenicama koje označavaju argument događaja i referencijalnim imenicama}

Sledeći parovi imenica ilustruju imenice koje mogu da pripadaju i imenicama koje označavaju argument događaja i referencijalnim imenicama. U prvom primeru upotrebljena je imenica koja označava argument događaja, a u drugom referencijalna imenica:

... tajno prikuplja važne vojne, ekonomske i druge podatke u korist neprijatelja, neke druge države, ustanove i sl, uhoda, podmetač, doušnik.

Nožem prvo odvojiti strane kalupa od mase, zatim dno suda, ako je moguće, a potom sud poklopiti tanjirom ili podmetačem za torte, prevrnuti ga i lakim i sigurnim pokretom istresti sadržinu. 
Tačno je sve što je izneto i, što je najbolje, ni najiskusniji čitač kriminalne rubrike neće osetiti da je nešto prećutano.

Tako, na primer, kasirka u samoposluzi koristi čitač prugastog koda (engl . bar code) kojim se čita podatak utisnut na ambalaži različite robe.

... graničar - rudarski nadzornik - posl. kamskih električara - ruk. transportnih traka - ruk. radilišta u jami - jamskimerač - ruk. ventilacione stanice - jamski mazač - sigmalista - pom. signaliste - radnik na grabuljaru - pumpar u jami - pom ... Osim nje u upotrebi je i elektronski merač "geomagnetometar".

Paja Jovanović nije samo majstor slikarskog zanata, umetnik visoke klase, on je ujedno i majstor, umetnik života, mudri upravljač svojim darovima.

Delovi bicikla su: 1) upravljač, 2) prednje svetlo, 3) ram, 4) sedalo, 5) točkovi, 6) pedale, 7) zadnje svetlo "mačje oko", 8) pumpa ...

On piše: "Oko 1850. god., neki gatar iz Šljivovice kazivao ljudima ovo.

Na sreću, imaju gatar pa lako mogu da ucmekaju divlju svinju i reše problem.

... pomalo zapostavljene knjige koje imaju vrednost i zaslužuju pažnju savremenog čitaoca, a koje će privlačiti pažnju čitališta i u novom veku i milenijumu. Godinu dana posle Berlinskog kongresa, pirotski, niški, toplički i vranjski okrug dobijaju čitališta kako bi pomogla širenju prosvete i jačanju nacionalne svesti, posle ropstva pod Turcima.

Verni pratilac i beležnikzbivanja u ovom gradu, "Glas Trebinja" objavljuje: "Ovih dana komisija koju su sačinjavali Nikola Kovač, profesor ...

Pomalo rasejano, O’Brajen pipnu po džepovima, zatim izvadi beležnik s kožnim koricama i zlatnu hemijsku olovku.

Referencijalna imenica čitalište spada u imenice sa značenjem mesta. Ostale referencijalno upotrebljene imenice u ovim primerima spadaju $\mathrm{u}$ imenice sa značenjem predmeta. Među referencijalnim imenicama sa značenjem predmeta, imenice čitač i merač mogu se svrstati u podgrupu imenica koje označavaju merne instrumente ili neke tehničke pojmove (takve su i imenice brojač, provodnik...). Imenica beležnik u svom referencijalnom značenju spada u imenice koje se odnose sa na knjigu, odnosno hartiju (takve su i imenice uverenje, dopisnica...). Imenice podmetač, upravljač i gatar takođe imaju značenje određenih predmeta.

Još je manji broj imenica koje pokazuju dvosmislenost između imenice koja označava događaj i referencijalne imenice. 


\section{Imenice koje pripadaju i imenicama koje označavaju događaj i referencijalnim imenicama}

Naredni primeri ilustruju imenice koje mogu da pripadaju i imenicama koje označavaju događaj i referencijalnim imenicama. U prvom primeru upotrebljena je imenica koja označava događaj, a u drugom primeru referencijalna imenica:

Urna datira iz perioda od tridesetak godina nakon Isusovog raspeća i nosi ime Josifa, njegovog oca, i Jovana, njegovog brata i vođe rane hrišćanske crkve u Jerusalimu.

Visoko, u vrhu ikonostasa, svetlelo je pred raspećem kandilo.

Bila je sva opremljena ukradenim stvarima sa putovanja; od pribora za jelo do čaša i pepeljara.

Uskoro smo stigli na noćište, gde smo već zatekli pripremljeno i postavljeno jelo.

Šverc je pak sveta radnja.

Posetom njegovom muzeju može da se vidi kako je izgledala kovačka radnja a kako berbernica, obućarska, šeširdžijska, užarska, krojačka radionica.

Punjenje baterije traje nekoliko časova, ali se može koristiti i poseban punjač koji 80 odsto baterije puni za pola sata.

... našli jedan ručni bacač kineske proizvodnje, jedan ručni bacač “zolja”, četiri mine za ručni bacač, pet barutnih punjenja za ručni bacač, dve tromblonske mine šest upaljača za minobacačke granate $82 \mathrm{~mm}$ i jednu granatnu za ABG kalibra $40 \mathrm{~mm}$.

Bile su potrebne članske karte (moglo je ući 200 do 250 osoba) i pri ulazu dame su uvek imale prednost, čak iako nisu imale novca za ulaznicu.

Grmalj im priđe s leđa, Milenu uhvati za jednu a mladića za drugu ruku i povede ih u obližnji ulaz.

Ovi primeri ilustruju slučajeve leksikalizacije glagolskih imenica, njihovog potpunog poimeničavanja. Ukoliko glagolske imenice posmatramo kao jedan kontinuum, na jednom kraju tog kontinuuma su prave glagolske imenice, koje, kao i glagoli od kojih su nastale, označavaju radnju, stanje ili zbivanje, odnosno neki događaj, a na drugom kraju su referencijalne glagolske imenice, koje imaju neko referencijalno značenje, koje je karakteristično za obične, prototipične imenice. Navedeni primeri pokazuju potpunu transpoziciju iz jedne kategorije (glagola) u drugu kategoriju (imenicu). 
Najmanje je primera sa imenicama koje mogu da pripadaju i imenicama koje označavaju događaj i imenicama koje označavaju argument događaja.

\section{Imenice koje pripadaju i imenicama koje označavaju događaj i imenicama koje označavaju argument događaja}

Registrovane su samo dve imenice dvosmislene između značenja događaja i značenja argumenta događaja. U sledećim parovima primera u prvom primeru upotrebljena je imenica koja označava događaj, a u drugom imenica koja označava argument događaja:

Pratnja će se organizovati po potrebi, a najviše tri puta u toku dana.

... SPO, osim u par slučajeva kada je, verovatno po nečijem naređenju, objašnjavano da su se predsednik SPO i njegova pratnja kretali brzinom većom od propisane kao da je to najbitnije u celom slučaju.

Čuvar porodičnog blaga Bertalan Nađ je na radnom mestu zadužen za obezbeđenje novčanih pošiljki.

Obezbeđenje ga zaustavi, pregleda mu torbu i uzme ličnu kartu.

Može se pretpostaviti da je razlog za mali broj ovakvih primera (u odnosu na druge gore navedene dvosmislene imenice) to što su ove dve potkategorije glagolskih imenica ,najbliže”, najsličnije jedna drugoj. Na pomenutoj skali glagolskih imenica gde su na jednom kraju imenice sa značenjem događaja, kao najsličnije glagolima, a na drugom kraju referencijalne, ,prave” imenice, imenice sa značenjem argumenta događaja su odmah do imenica sa značenjem događaja. One su posle imenica sa značenjem događaja najsličnije glagolima, zatim su tu rezultativne imenice, $\mathrm{i}$ na kraju su referencijalne imenice, koje nemaju nikakve sličnosti sa glagolima, osim što su glagolskog porekla. Između ,susednih” potkategorija ili $\mathrm{u}$ istraživanju nije zabeležen nijedan primer dvosmislene imenice (između rezultativnih i referencijalnih imenica) ili samo dva, kao u primeru imenica koje su dvosmilene između imenice sa značenjem događaja i imenice sa značenjem argumenta događaja. 


\section{Zaključak}

Istraživanje je zabeležilo četiri grupe polisemičnih, dvosmislenih glagolskih imenica u savremenom srpskom jeziku: imenice koje pripadaju i imenicama koje označavaju događaj i rezultativnim imenicama; imenice koje pripadaju i imenicama koje označavaju argument događaja i referencijalnim imenicama; imenice koje pripadaju i imenicama koje označavaju događaj i referencijalnim imenicama i imenice koje pripadaju i imenicama koje označavaju događaj i imenicama koje označavaju argument događaja. Najveći polisemični kapacitet imaju imenice sa značenjem događaja - one mogu biti dvosmislene u odnosu na sve tri preostale potkategorije glagolskih imenica (imenice sa značenjem argumenta događaja, rezultativne i referencijalne imenice). Posle njih slede imenice sa značenjem argumenta događaja i referencijalne imenice. One mogu biti dvosmilene u odnosu na dve potkategorije glagolskih imenica - dvosmislene su međusobno i još u odnosu na imenice sa značenjem događaja. Rezultativne imenice mogu biti dvosmislene samo u odnosu na imenice sa značenjem događaja.

Polisemični kapacitet imenica sa značenjem događaja može se objasniti njihovom najvećom sličnošću sa glagolima u odnosu na sve druge potkategorije glagolskih imenica. Može se pretpostaviti da su se sva druga značenja glagolskih imenica razvila iz značenja događaja. Procesom poimeničavanja imenica sa značenjem događaja kao pravih glagolskih imenica, gubljenjem njihovih tipično glagolskih osobina, nastala su sva druga značenja koja glagolske imenice imaju, počevši od značenja argumenta događaja, preko rezultativnog, pa do referencijalnog značenja.

Pitanje kojim se ovaj rad nije bavio, a koje bi bilo zanimljivo istražiti, jesu tipovi glagola iz kojih se ove dvosmislene imenice izvode. Bilo bi interesantno videti da li postoji određena korelacija između tipa dvosmislenosti glagolskih imenica i tipa glagola iz kojih su te imenice izvedene.

\section{Literatura}

Alexiadou, A. (2001). Functional Structure in Nominals: Nominalization and Ergativity. Amsterdam/Philadelphia: John Benjamins Publishing Company.

Alexiadou, A. (2009). On the role of syntactic locality in morphological processes: the case of (Greek) derived nominals. Iz: A. Giannakidou \& M. 
Rathert (ed.) QUANTIFICATION, DEFINITENESS AND NOMINALIZATION, 253-280. Oxford: Oxford University Press. http://ifla.uni-stuttgart. de/institut/mitarbeiter/artemis/ artemissaabrrev.pdf

Belić, A. (1933). O građenju glagolskih imenica na -nje i -će. Naš jezik I, 262-268. Borer, H. (1993). Parallel Morphology. University of Massachusetts.

Borer, H. (2003). Exo-skeletal vs. endo-skeletal explanations: syntactic projections and the lexicon, Polinsky, M. and J. Moore, eds. Explanation in Linguistic Theory. Stanford: CSLI.

Borsley, R., Kornfilt, J. (2000). Mixed extended projections. Iz: Borsley, R. (Ed.) Syntax and Semantics 22: The Nature and Function of Syntactic Categories, 101-131. Academic Press, New York.

Chomsky, N. (1970). Remarks on Nominalization. Iz: Jacobs, R. \& Rosenbaum, P. (ed.), Readings in English Transformational Grammar. Waltham, Mass: Ginn and Company, 184-221.

Fu, J., Borer, H. \& Roeper T. (2001). The VP within nominalizations: evidence from adverbs and the VP anaphor do so. Natural Language and Linguistic Theory 19, 549-582.

Grimshaw, J. (1990). Argument Structure. Cambridge, Mass.: MIT Press.van Hout, A. \& Roeper, T. (1998). Events and Aspectual Structure in Derivational Morphology. MIT Working Papers in Linguistics 32, 175-220.

Klajn, I. (2003). Tvorba reči u savremenom srpskom jeziku, II. Beograd: Zavod za udžbenike i nastavna sredstva/Novi Sad: Matica srpska/Beograd: Institut za srpski jezik SANU.

Kovačević, B. (2012). Sintaksičko-semantičke kategorije glagolskih imenica. Doktorska disertacija, Filološki fakultet u Beogradu.

Kovačević, B. (2016). Glagolske imenice u savremenoj lingvističkoj teoriji. Beograd: Filološki fakultet

Lebeaux, D. (1986). The Interpretation of Derived Nominals. Iz: A. M. Farley, P. T. Farley and K. E. McCullogh (ed.), CLS Papers from the General Session at the Twenty-Second Regional Meeting of the Chicago Linguistic Society, 231-247.

Picallo, C. (1991). Nominals and Nominalizations in Catalan. Probus 3/3, 271-316.

Radić, P. (1988). Glagolske imenice na -nje i -će (obrazovanja od svršenih glagola). Književnost i jezik, god. 35, br. 1, 47-54.

Sleeman, P. \& Brito, A. M. (2010a). Nominalization, Event, Aspect, and Argument Structure: a Syntactic approach. Iz: M. Duguine, S. Huidobro \& N. Madariaga (ed.) Argument Structure from a Crosslinguistic Perspective, 113-129. Amsterdam \& Philadelphia: John Benjamins. http://repositorioaberto.up.pt/ bitstream/10216/17811/2/anamariabritosleeman000078579.pdf

Sleeman, P. \& Brito, A.M. (2010b). Aspect and argument structure of deverbal nominalizations: a split $v$ P analysis. Iz: A. Alexiadou \& M. Rathert (ed.) 
Nominalizations across Languages and Frameworks, 191-209. Berlin: Mouton de Gruyter. http://home.medewerker.uva.nl/a.p.sleeman/bestanden/ Sleeman\&Brito \%20Mouton.pdf

Terzić, A. (1969). Strukturno-semantičke odlike glagolskih imenica tvorbenog tipa -nie, -enie, u ruskom i -nje-će u srpskohrvatskom jeziku. Anali Filološkog fakulteta IX, 27-93.

Vuković, J. (1950). Glagolske imenice na -nje i -će. Pitanja savremenog književnog jezika, sv. 1 (1949), 40-53, sv. 2 (1950), 149-171.

Borko Kovačević

\section{Summary \\ POLYSEMIC DEVERBAL NOUNS IN THE CONTEMPORARY SERBIAN LANGUAGE}

This paper discusses polysemic deverbal nouns in Serbian. There are four groups of these nouns: nouns that belong to the event nouns and to the argument nouns; nouns that belong to the event nouns and to the result nouns; nouns that belong to the event nouns and to the referential nouns; nouns that belong to the argument nouns and to the referential nouns. Event nouns have the greatest polysemic capacity.

Keywords: deverbal nouns, polysemy, Serbian 